\title{
Variance Ratio Tests of the Random Walk in the BRVM
}

\author{
Konan Léon N'DRI ${ }^{1}$ \\ ${ }^{1}$ University Felix Houphouet Boigny, Abidjan, Côte d'Ivoire. \\ Correspondence: Konan Léon N'DRI, University Felix Houphouet Boigny, Abidjan, Côte d'Ivoire.
}

Received: March 30, 2015

Accepted: April 14, 2015

Available online: April 23, 2015

doi:10.11114/aef.v2i2.751

URL: http://dx.doi.org/10.11114/aef.v2i2.751

\begin{abstract}
The hypothesis that a stock market price index follows a random walk is tested for the regional stock market of the West African Economic and Monetary Union called the Bourse Régionale des Valeurs Mobilières (BRVM) using the Lo and MacKinlay (1988), the Chow and Denning (1993), and the Wright's (2000) rank-based variance ratio tests. The tests are applied to daily stock price index over the period January 2, 2002 to December 31, 2004, and all three tests reveals that the null hypothesis of random walk can not be rejected in the BRVM. This result is an indication that the BRVM is weak form efficiency and has various implications for investors and regulators. The first would engage their savings into productive investments opportunities and the second will limit their intervention as securities are fairly priced.
\end{abstract}

Keywords: Stock market efficiency, Random walk hypothesis, Variance ratio tests, BRVM.

JEL Classification: G14; G15; C14.

\section{Introduction}

A capital market is said to perform four important functions: capital allocation, price discovery, risk management, and good governance. It is with this view that on 18 December 1996, the member States of the West African Economic and Monetary Union set up the Regional Stock Market known as the Bourse Régionale des Valeurs Mobilières (hereafter the BRVM). For the BRVM to be able to realize all these functions, it is expected to be efficient.

A capital market is efficient with respect to some information set if prices reflect instantly and fully all relevant available information (Fama, 1965). In such a market, one cannot make profit by trading on the basis of that information set on a continuous basis. Three levels of market efficiency are distinguished according to the completeness and rapidity of information incorporation into securities prices (Fama, 1970). First, the weak-form efficiency refers to the ability of securities prices to fully reflect all the information contained in the history of past prices or returns. Second, the semi-strong efficiency is obtained if security prices fully reflect all public information. Third, the strong-form efficiency holds when both public and private information are impounded into the prices. Fama (1991) reclassified these three forms of efficiency in terms of the methodologies used to evaluate efficiency. Thus, the strong form efficiency bears on tests of private information, and the semi-strong form concerns tests of event studies. The weak form efficiency refers to tests of returns predictability.

Market efficiency has many implications for investors and regulators. Market regulators will limit their intervention as securities are fairly priced. If the market is not efficient, regulatory bodies should regulate the operations and the capital allocation process to ensure that securities are correctly prices thereby leading to an efficient capital market. In an efficient capital market, investors will be more willing to invest their savings in the market for they believe the securities they trade in are accurately priced. They will thus allocate scare funds to the highest value-added projects. It will also be easier for firms to raise capital because the market determines the price at which equity or securities holders are willing to exchange claims on a firm's future cash flows.

Given the importance of capital market efficiency, many empirical tests on weak-form market efficiency have been largely carried out on developed markets (Fama, 1965, 1970; Poterba \& Summers, 1988; Lo \& Mckinaly, 1988; Hudson, Dempsey, \& Keasey, 1996; Nicolaas, 1997; Seiler \& Rom, 1997; Worthington \& Higgs, 2004; Borges, 2008; Ito \& Sugiyama, 2009 amongst others) and, on emerging equity markets (Branes, 1986; Chan, Gup, \& Pan, 1992; Ayadi \& Pyun, 1994; Urrutia, 1995; El-Erian \& Kumar, 1995; Claessens, Dasgupta, \& Glen, 1995; Laurence, Ca, \& Qian, 1997; Ojah \& Karemera, 1999; Dezlan, 2000; Lee, Chen, \& Rui, 2001; Cheung \& Coutts, 2001; Regulez \& Zarraga, 2002; Ryoo \& Smith, 2002; Hajeck, 2002; Buguk \& Brorsen, 2003; Padhan, 2009; Lima \& Tabak, 2004, Chung, 2006, Hoque, 
Kim, \& Pyun, 2007). Tests of weak-form efficiency on frontier markets are however quasi-inexistent (Dickison \& Muragu, 1994; Appiah-Kusi \& Menyah, 2003; Omran \& Farrar, 2006; Mlambo \& Biekpe, 2007; Al-Khazali, Ding, \& Pyun, 2007; Enowbi, Guidi, \& Mlambo, 2009) and, particularly inexistent for the BRVM (N'dri, 2007).

This paper intends to fill this gap by contritbuting to the existing empirical literature on the random walk hypothesis in the BRVM through three variance ratio tests. This paper revisits on the other hand the paper by N'dri (2007) who used the statistics of Box-Pierce, Box-Pierce corrected for heteroskedasticity and runs to test for weak form efficiency in the BRVM. My results show that the tests cannot reject the hypothesis of random walk in the BRVM thereby implying that the BRVM is weak form efficient.

The rest of the paper is organized as follows. After the introduction section, an overview of the BRVM is provided by section 2. Section 3 presents methodology of the variance ratio tests and describes the data. Section 4 exposes the empirical results and their analysis and section 5 concludes the paper.

\section{Overview of the BRVM}

The Bourse Régionale des Valeurs Mobilières (BRVM) is the regional stock market of Benin, Burkina-Faso, Guinea Bissau, Côte d'Ivoire, Mali, Niger, Senegal, and Togo, eight French speaking countries which form the West African Economic and Monetary Union (WAEMU). The BRVM was set up in December 18, 1996 and began its organizational and promotional activities of the regional securities market by September 16, 1998. Price determination at the BRVM is done by two fixing sessions. The first one fixes security prices by matching bid and ask orders collected before the quotation. The second takes place before the end of the trading session to enable "unlisted" and/or "reserved" stocks from the first fixing to be traded. Trading on the BRVM is electronic via a satellite link. Brokers located in the member countries send in their orders to the central site located in Abidjan which hosts the headquarter of the regional stock market. There are two sections for stocks and one for bonds on the BRVM with differing listing conditions. Listing on the first section for stocks requires at least five certified annual accounts whereas listing on the second section requires at least two years of certified accounts; the first section necessitates a market capitalization of at least 500,000,000 CFA francs against at least 200,000,000 CFA francs for the second; in the first section, at least $20 \%$ of public shares must be distributed whereas in the second section there is a commitment to distribute at least $20 \%$ of capital to the public within two years, or 15\% in the event of a share capital increase. Listing on the bond section requires that the total number of shares issued be higher than 25,000 with a face value of at least 500,000,000 CFA francs. It is worth to note that the common currency for the WAEMU member States is the CFA franc (Communauté Financière Africaine). 1 Euro = 655.957 CFA Franc pegged at a fixed rate. The BRVM 10 which comprises the ten most active companies and the BRVM Composite that includes all securities listed on the exchange represent the activities of the regional stock market. Table 1 from N'dri (2007) below provides some statistics on the BRVM.

Table 1. Selected Figures of the BRVM

\begin{tabular}{|c|c|c|c|c|}
\hline Capitalization & $31 / 12 / 2002$ & $31 / 12 / 2003$ & $31 / 12 / 2004$ & 29/08/ 2005 \\
\hline BRVM 10 & $\begin{array}{r}465634264 \\
590\end{array}$ & 617337595495 & 607239551350 & 766467440025 \\
\hline BRVM Composite & 832398094700 & 858140223580 & 1005047884085 & 1094198936835 \\
\hline \multicolumn{5}{|l|}{ Number of firms } \\
\hline BRVM 10 & 10 & 10 & 10 & 10 \\
\hline BRVM Composite & 39 & 39 & 39 & 39 \\
\hline \multicolumn{5}{|l|}{ Some measures } \\
\hline Volume traded of stocks & 4823 & 2994 & 2031 & 1033 \\
\hline Value traded (CFAfr) & 171254520 & 72584325 & 35861220 & 47493520 \\
\hline \# of transations & 30 & 85 & 28 & 25 \\
\hline \# of securities traded & 9 & 15 & 8 & 8 \\
\hline
\end{tabular}

Notes: 1 Euro=655.957 CFA Fr. The CFA Fr is the currency unit of the West African Economic and Moneta Union (WAEMU) eight (8) member States.

Source: N'dri (2007), p. 108

\section{Methodology}

In an efficient capital market, the prices of securities fully reflect all available information, and hence securities' returns 
are expected to follow an unexpected process or random walk. A random process states that future security prices can not be predicted on the basis of past price movements. To an investor, it implies that investment strategies based on past information will not necessarity yield higher returns than a portfolio consisting of randomly picked stocks (Malkiel, 2003). Many statistical tools have been used to test for random walk processes but this paper limits itself to three variance ratio tests exposed below.

The random walk is a method widely used to test for the weak form market efficiency. I consider that stock prices follow a simple random walk process with drift.

$$
\begin{aligned}
& p_{t}=\mu+p_{t-1}+\varepsilon_{t}, \varepsilon_{t} \rightarrow I I D\left(0, \sigma^{2}\right) \\
& R_{t}=p_{t}-p_{t-1}
\end{aligned}
$$

Where $\mu$ is the expected return of $R_{t} \cdot p_{t}$ and $p_{t-1}$ are the natural logarithm of stock price index at $t$ and $t-1$ respectively. $R_{t}=p_{t}-p_{t-1}$ is the continuously compounded return not adjusted for dividends. $\varepsilon_{t}$ is the white noise independent and identically distributed with mean 0 and variance $\sigma^{2}$. There are three versions of the random walk depending on the distribution of disturbance terms (Campbell, Lo, \& MacKinlay, 1997).

\subsection{Lo and Mackinlay variance ratio tests}

It is agreed that a unit root is a necessary but not a sufficient condition for a random walk process since unit roots processes can have predictable elements within whereas a random walk for stock prices means that returns must be uncorrelated and have a unit root. Variance ratio tests for random walks therefore focus on uncorrelated residuals and are preferable to unit root tests. I expose in this section the Lo and Mackinlay (1988) variance ratio tests also referred to as individual variance ratio tests. After the authors, if a series follows a random walk with uncorrelated increments in $p_{t}$, the variance of its $q$-differences would be $q$ times the variance of its first differences as follows:

$$
\operatorname{Var}\left(p_{t}-p_{t-q}\right)=q \operatorname{Var}\left(p_{t}-p_{t-1}\right)
$$

Where $q$ is any positive integer and $p_{t}$ and $p_{t-q}$ are the natural logarithm of prices at $t$ and $t-q$ respectively. $\operatorname{Var}($.) refers to the variances. The variance ratio is then:

$$
\operatorname{VR}(q)=\frac{\frac{1}{q} \operatorname{Var}\left(R_{t}(q)\right)}{\operatorname{Var}\left(p_{t}-p_{t-1}\right)}=\frac{\sigma^{2}(q)}{\sigma^{2}(1)}
$$

The $V R(q)=1$ under the null hypothesis of the random walk thereby implying weak form market efficiency but not vice versa. Lo and Mackinlay generate the asymptotic distribution of the estimated variance ratio and derive two tests statistics, $Z(q)$ and $Z^{*}(q)$ under the null hypothesis of homoskedastic increments and heteroskedastic increments random walk respectively as follows:

$$
Z(q)=\frac{\operatorname{Var}(R(q+1)}{\sqrt{\theta(q)}} \stackrel{a}{\longrightarrow} N(0,
$$

where $\theta(q)=\frac{2(2 q-1)(q-1)}{3 q(n q)}$

$$
Z^{*}(q)=\frac{\operatorname{Var}(R(q)-1)}{\sqrt{\theta^{*}(q)}} \stackrel{a}{\longrightarrow} N(0,1)
$$

$$
\begin{aligned}
& \text { where } \theta^{*}(q)=\sum_{j=1}^{q-1}\left[\frac{2(q-j)}{q}\right]^{2} \hat{\delta}(j) \\
& \text { and } \hat{\delta}(j)=\frac{\sum_{t=j+1}^{n q}\left(p_{t}-p_{t-1}-j^{2}{ }^{2}\left(p_{t-j}-p_{t-j-1}-\mu\right)^{2}\right.}{\left[\sum_{t-1}^{n q}\left(p_{t}-p_{t-1}-\hat{\mu}\right)^{2}\right]^{2}}
\end{aligned}
$$

When the null hypothesis holds, $Z(q)$ and $Z^{*}(q)$ have an asymptotic standard distribution with mean zero and unit 
standard deviation.

\subsection{Chow and Denning multiple variance ratio tests}

The Lo and MacKinlay variance ratio tests have two main limitations. First, they focus on testing for individual variance ratios for specific aggreatation interval $q$, but the random walk hypothesis requires that $V R(q)=1$ for all $q$. Second, they are asymptotic tests whose sampling distributions are biased and right skewed in finite samples (Charles and Darnè, 1993). To control for the test size and reduce errors, Chow and Denning (1993) propose a simple multiple variance ratio test (MVR) which uses Lo and MacKinlay's test statistics as the studentized maximum modulus (SMM) statatistics. For a single variance ratio, under the null hypothesis $V R(q)=1$ and hence $M_{r}(q)=V R(q)-1=0$. Consider a set of $m$ variance ratio test $\left\{M_{r}\left(q_{i}\right) \mid i=1,2, \ldots \ldots ., m\right\}$ associated with the set of aggregate intervals $\left\{q_{i} \mid i=1,2, \ldots \ldots ., m\right\}$. Under the null hypothesis, there are multiple sub-hypotheses:

$$
\begin{aligned}
& H_{0 i}: M_{r}\left(q_{i} \neq 0 \text { fo } i 1,2, \ldots m .\right. \\
& H_{1 i}: M_{r}\left(q_{i} \neq 0 \text { for any } 1,2, \ldots\right.
\end{aligned}
$$

Rejection of any one or more $H_{0 i}$ rejects the random walk null hypothesis. Let a set of Lo and MacKinlay test statistics $\left\{Z\left(q_{i}\right) \mid i=1,2, \ldots \ldots, m\right\}$. Since the random walk hypothesis is rejected if any one of the estimated variance ratios is significantly different from one, it is worthwhile considering only the maximum absolute value in the set of test statistics. The core of Chow and Denning's MVR test is based on Hochberg (1974).

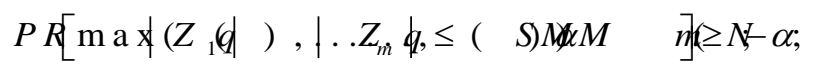

$\operatorname{SMM}(\alpha ; m ; N)$ is the upper $\alpha$ point of the Studentized Maximum Modulus (SMM) distribution with parameters $m$ and $N$ degrees of freedom. Critical values are provided by Miller (1981). Asymptotically, when $N$ is infinite, $\lim _{N \rightarrow \infty} \operatorname{SMM}(\alpha ; m ; N)=Z_{\alpha^{*} / 2}$, where $Z_{\alpha^{*} / 2}$ is the standard normal with $\alpha^{*}=1-(1-\alpha)^{1 / m}$.

The size of the MVR test is controlled by comparing the calculated value of the standardized Lo and MacKinlay test statistics, either $Z\left(q_{i}\right)$ or $Z^{*}\left(q_{i}\right)$ with the SMM critical values. If the maximum absolute value of, say $Z^{*}\left(q_{i}\right)$ is greater than the critical value of a predetermined significance level, then the random walk hypothesis is rejected.

\subsection{Wright Non Parametric Variance Ratio Tests}

Wright (2000) proposes the alternative non-parametric variance ratio test using ranks and signs of returns and demonstrates that they have better power properties than other variance ratio tests for two reasons: first, it is likely to compute the exact distribution; so one needs not to be concerned about the size distortions due to the need to appeal to any asymptotic approximation. Second, tests based on ranks and signs are more powerful than other tests when the data are higly non-normal. I consider in this paper the rank based variance ratio. Let $r\left(y_{t}\right)$ be the rank of $y_{t}$ among $y_{1}, y_{2}, \ldots \ldots ., y_{T}$. Define the standardized rank $r_{1 t}$ with sample mean 0 and sample variance 1 , and the Van der Waerden rank scores $r_{2 t}$ with sample mean 0 and sample variance approximately equal to 1 as follows:

$$
\begin{aligned}
& r_{1 t}=\frac{\left(r\left(y_{t}\right)-\frac{T+1}{2}\right)}{\sqrt{\frac{(T-1)(T+1)}{12}}} \\
& r_{2 t}=\phi^{-1} \frac{r\left(y_{t}\right)}{T+1}
\end{aligned}
$$

where $\phi$ is the standardized normal cumulative distribution function and $\phi^{-1}$ is its inverse function. Wright's variance ratio test statistics are obtained by substituting $r_{1 t}$ and $r_{2 t}$ in place of the returns in the Lo and MacKinlay homoskedastic test statistic $Z(q)$. The rank-based variance ratio test statistics $R_{1}$ and $R_{2}$ are defined as follows:

$$
\begin{aligned}
& R_{1}=\left(\frac{\frac{1}{T k} \sum_{t=k}^{T}\left(r_{1 t}+r_{1 t-1}+\ldots . .+r_{1 t-k+1}\right)^{2}}{\frac{1}{T} \sum_{t=1}^{T} r_{1 t}^{2}}-1\right) \times\left(\frac{(2(2 k-1)(k-1))}{3 k T}\right)^{-1 / 2} \\
& R_{2}=\left(\frac{\frac{1}{T k} \sum_{t=k}^{T}\left(r_{2 t}+r_{2 t-1}+\ldots \ldots+r_{2 t-k+1}\right)^{2}}{\frac{1}{T} \sum_{t=1}^{T} r_{2 t}^{2}}-1\right) \times\left(\frac{(2(2 k-1)(k-1))}{3 k T}\right)^{-1 / 2}
\end{aligned}
$$


Under the i.i.d. null hypothesis, the exact sampling distribution of the statistics may be approximated using a permutation bootstrap.

\subsection{The Data and Their Properties}

The data used in this study are daily closing prices on the BRVM10 index expressed in CFA Franc obtained from the Official Newsletter of the Regional Stock Market website. The study period ranges from 2 January 2002 to 31 December 2004 for a total of 742 observations. Choosing the BRVM10 is guided by the facts that it comprises ten of the most actively traded stocks of the regional stock market and accounts for more than $70 \%$ of the total market capitalization (See Table 1).

Implementing variance ratio tests requires that series be stationary. To determine whether the series is stationary or not, I apply the Phillips and Perron (1988) test. The interest of the test is to inform on the need to differentiate the series under study. The test is robust to heteroskedasticity and is presented in Table 1 below with the usually used lags, $T^{1 / 4}$, where $T$ is the number of observations.

Table 2. Tests of Phillips-Perron

\begin{tabular}{cccc}
\hline Series & models & lags & PP Stat. \\
\hline \multirow{2}{*}{ BRVM10 } & 1 & 5 & $-28,100^{*}$ \\
\cline { 2 - 4 } & 2 & 5 & $-28,116^{*}$ \\
\cline { 2 - 4 } & 3 & 5 & $28,271^{*}$ \\
\hline
\end{tabular}

Notes: Model 1: model without constant and trend; Model 2: model with constant without trend; Model 3: model with constant and deterministic trend. PP Stat. are the Phillips-Perron statistics compared with critical values of -1.61 for model $1 ;-2.56$ for model 2; and -3.13 for model 3. * means significant at the $10 \%$ level.

Results from Table 2 show that all PP statistics are inferior to the critical values at the $10 \%$ significant level. The series is therefore stationary. This result is contradiction with that of financial series that are generally integrated of order 1 . Given that result, I use for the remaining tests, the continuously compounded returns calculated as first differences in the logs of the stock price indices, $R_{t}=p_{t}-p_{t-1}$. The descriptive statistics are shown in Table 3 below.

Table 3. Summary Statistics

\begin{tabular}{lccccccc}
\hline Series & $\mathrm{T}$ & Mean & SD & Skewness & Kurtosis & J.B. & ARCH(5) \\
\hline & & & & & & & \\
BRVM10 & 741 & 0.027 & 0.810 & -0.758 & 16.409 & $5621^{*}$ & $19.611^{*}$ \\
& & & & & & $(0.000)$ & $(0.001)$ \\
\hline
\end{tabular}

Notes: $\mathrm{T}$ is the number of observations; SD is the standard deviation; * means significant at 5\%. JB is the Jarque-Bera statistic; $\mathrm{ARCH}(5)$ is the $\mathrm{ARCH}$ test for homoskedasticity with 5 lags; $p$-values are in parentheses.

Table 3 presents descriptive statistics. The kurtosis is very much larger than 3 , the kurtosis for a normal distribution. This suggests that in the BRVM, large market surprises of either sign are more likely to be observed at least unconditionally. The p-value of 0.000 associated with the Jarque and Bera statistic indicates that the null hypothesis of normality is rejected. The skewness of -0.758 indicates that the distribution is negatively skewed relative to the normal distribution ( 0 for normal distribution). This result is an indication of a non symmetric series. These prospective non linearities might signal the presence of autoregressive conditional heteroskedasticity (ARCH) effects which are common to financial series. For further investigations, I apply the Engle (1982) test of homoskedasticity to the series with lag length selected based on Akaike and Schwartz information criterion. The $p$-value of 0.001 associated with the $\mathrm{ARCH}$ test indicates that the null hypothesis of homoskedasticity is rejected. The series exhibits therefore the presence of conditional heteroskedastic and is thereby not independent and identically distributed.

\section{Empirical Results and Analysis}

This section reports results of the various variance ratio tests on the continuously compounded returns of the stock price index (BRVM10). I use 1-day as my base observation and I test the random walk hypothesis by calculating the various variance ratio tests for sampling intervals of $2,4,8$, and 16 days. 
Tables 4 and 5 provide the results of individual and multiple variance ratio tests respectively. Individual variance ratio tests regroup tests of the Lo and MacKinlay, and the Wright's rank-based variance ratio tests while multiple variance ratio tests refer to the Chow and Denning variance ratio tests.

Table 4. Estimates of Individual Variance Ratio Tests

\begin{tabular}{lllll}
\cline { 2 - 4 } & \multicolumn{4}{c}{ Return horizon $q$} \\
\cline { 2 - 5 } & 2 & 4 & 8 & 16 \\
\hline$V R(q)$ & 0.968 & 0.966 & 0.994 & 1.072 \\
$Z(q)$ & $-0.879(0.380)^{*}$ & $-0.492(0.623)^{*}$ & $-0.060(0.952)^{*}$ & $-0.448(0.654)^{*}$ \\
$Z^{*}(q)$ & $-0.552(0.380)^{*}$ & $-0.343(0.380)^{*}$ & $-0.044(0.380)^{*}$ & $0.366(0.380)^{*}$ \\
$R_{1}$ & $1.009(0.380)^{*}$ & $1.016(0.380)^{*}$ & $0.992(0.380)^{*}$ & $1.028(0.380)^{*}$ \\
$R_{2}$ & $1.008(0.380)^{*}$ & $1.024(0.380)^{*}$ & $1.030(0.380)^{*}$ & $1.097(0.380)^{*}$
\end{tabular}

Notes: $\operatorname{VR}(q)$ is the Lo and Mackinlay variance ratio for q-day returns; $Z(q)$ and $Z^{*}(q)$ are the asymptotic normal test statistics under homoskedasticity and heteroskedasticity, respectively. $R_{1}$ and $R_{2}$ are Wright's rank-based variance ratio test statistics; $p$ values are in parentheses; * indicates that the variances ratios are not statistically different from 1 at $5 \%$ level significance.

The results from Table 4 show that none of the Lo and MacKinlay test statistics under homoskedasticy and heteroskedasticity at any integer $q$ is significant since all the p-values are greater than 0.05 . Similarly, all the p-values associated with the Wright's rank-based test statistics $R_{1}$ and $R_{2}$ are all greater than 0.05 . These results are indications that the null hypothesis that variance ratios are statistically different from one can not be rejected. Therefore the random walk hypothesis can not be rejected thereby implying that the BRVM is weak form efficient.

These results from individual variance ratios are further investigated by the multiple variance ratio tests of Chow and Denning which require that $\operatorname{VR}(q)=1$ for all q-day returns for the random walk process to hold. Table 5 below reports results of the Chow and Denning multiple variance ratio tests.

Table 5. Estimates of Multiple Variance Ratio Tests

\begin{tabular}{lll}
\cline { 2 - 3 } & $\operatorname{Max}|\mathrm{z}|$ & $\operatorname{Max}\left|\mathrm{z}^{*}\right|$ \\
\hline Values & 0.879 & 0.552 \\
& $(0.852)$ & $(0.969)$ \\
\hline
\end{tabular}

Notes: Max $|\mathrm{z}|$ is the Chow and Denning homoskedastic statistic associated with period 2 individual test; Max $\left|\mathrm{z}^{*}\right|$ is the Chow and Denning heteroskedastic statistics of null hypothesis for all periods; $p$-values in parentheses are calculated using the studentized maximum modulus $\mathrm{m}=4$ and infinite degree of freedom.

It appears from Table 5 that the Chow and Denning maximum $|z|$ statistic of 0.8794 associated with the period 2 individual test and Chow-Denning joint (for all holding periods) test maximum $\left|\mathrm{z}^{*}\right|$ statistic of 0.552 have $p$-values of 0.852 and 0.969 respectively. These results imply that the random walk hypothesis can not be rejected; the BRVM is therefore weak form efficient.

The present result corroborates the study by N'dri (2007) who used tests of Box-Pierce and Box-Pierce corrected for heteroskedasticity, and the runs test to arrive at the conclusion that the BRVM is weak form efficient. This result has major implications for investors and market regulators. For investors, there is evidence that their return on investment will be guaranteed as their capital allocation will be directed towards productive investment opportunities, Ceteris paribus. Regulators on the other hand would find it necessary to reduce market interventions.

\section{Conclusion}

This paper has investigated the random walk hypothesis in the regional stock market of the West African Economic and Monetary Union called the Bourse Régionale des Valeurs Mobilières (BRVM) by adopting the Lo and MacKinlay (1988), the Chow and Denning (1993), and the Wright's (2000) rank-based variance ratio tests, using daily data on stock prices over the period 2 January 2002 to 31 December 2004.

The study reveals that all three variance ratio tests can not reject the null hypothesis of random walk thereby implying that the BRVM is weak form efficient. The study draws conclusions for investors and regulators. The former will not hesitate to engage their savings into prospective productive investment opportunities, and the latter would reduce their interventions in the market as securities are fairly priced. 


\section{References}

Al-Khazali, O. M., Ding, D. K., \& Pyun, C. S. (2007) A new variance ratio test of random walk in emerging markets: A revisit, The Financial Review, 42, 303-317. http://dx.doi.org/ 10.1111/j.1540-6288.2007.00173.x

Appiah-Kusi, J., \& Menyah, K. (2003) Return predictability in African stock markets, Review of Financial Economics, 12, 247-271. http://dx.doi.org/ 10.1016/S1058-3300(02)00073-3

Ayadi, O. F., \& Pyun, C. S. (1994) An application of variance ratio test to the Korean securities market, Journal of Banking \& Finance, 18, 643-658. http://dx.doi.org/ 10.1016/0378-4266(94)00012-3

Borges, M .R. (2010) Efficient market hypothesis in European stock markets, The European Journal of Finance, 16, 711-726. http://dx.doi.org/ 10.1080/1351847X.2010.495477

Branes, P. (1986) Thin trading and stock market efficiency: A case of the Kuala Lumpur Stock Exchange, Journal of Business Finance and Accounting, 13, 609- 617. http://dx.doi.org/ 10.1111/j.1468-5957.1986.tb00522.x

Buguk, C., \& Brorsen, B. W. (2003) Testing weak-form market efficiency: Evidence from the Istanbul Stock Exchange, International Review of Financial Analysis, 12, 579-590. http://dx.doi.org/ 10.1016/S1057-5219(03)00065-6

Campbell, J. Y., Lo, A. W., \& MacKinlay, A. C. (1997) The Econometrics of Financial Markets, Princeton University Press, Princeton.

Chan, K. C., Gup, B. E., \& Pan, M. S. (1992) An empirical analysis of stock prices in major Asian Markets and United States, The financial Review, 27, 289-307. http://dx.doi.org/ 10.1111/j.1540-6288.1992.tb01319.x

Charles, A., \& Darné, O. (2000) Variance ratio tests of random walk: An overview, Journal of Economic Surveys, 23, 503-527. http://dx.doi.org/ 10.1111/j.1467-6419.2008.00570.x

Cheung, K. C., \& Coutts, J. A. (2001) A note on weak form market efficiency in security prices: evidence from the Hong Kong stock exchange, Applied Economics Letters, 8, 407-410. http://dx.doi.org/ $10.1080 / 135048501750237865$

Chow, K. V., \& Denning, K. (1993) A simple multiple variance ratio test, Journal of Econometrics, 58, $385-401$. http://dx.doi.org/ 10.1016/0304-4076(93)90051-6

Claessens, S., Dasgupta, S., \& Glen, J. (1995) Return behaviour in emerging Stock Market, The world Bank economic Review, 9, 131-151. http://dx.doi.org/ 10.1093/wber/9.1.131

Dezelan, S. (2000) Efficiency of the Slovenian equity market, Economic and Business Review, 2, 61-83.

Dickinson, J. P., \& Muragu, K. (1994) Market efficiency in developing countries: a case study of the Nairobi Stock Exchange, Journal of Business Finance and Accounting, 21, 133-150. http://dx.doi.org/ 10.1111/j.1468-5957.1994.tb00309.x

El-Erian, M., \& Kumar, M. (1995) Emerging equity markets in middle eastern countries, IMF Staff Papers, 42, $313-343$. http://dx.doi.org/ 10.2307/3867575

Engle, R. F. (1982) Autoregressive Conditional Heteroscedasticity with Estimates of the Variance of U.K. Inflation, Econometrica, 50, 987-1008. http://dx.doi.org/ 10.2307/1912773

Enowbi, B. M, Guidi, F., \& Mlambo, K. (2010) Testing the weak-form market efficiency and the day of the week effects of some African countries, The African Finance Journal, 12, 1-26.

Fama, E. F. (1965) The behavior of stock market prices, Journal of Business, 38, 31-105.

Fama, E. F. (1970) Efficient capital markets: a review of theory and empirical work, Journal of Finance, 25, $387-417$. http://dx.doi.org/ 10.1111/j.1540-6261.1970.tb00518.x

Fama, E. F. (1991) Efficient capital markets II, Journal of Finance, 46, 1575-1617. http://dx.doi.org/ 10.1111/j.1540-6261.1991.tb04636.x

Hajek, J. (2002) Weak-form efficiency in the Czech equity market, Politicka Ekonomie, 50, 377-389.

Hochberg, Y. (1974) Some conservative generalizations of the T-method in simultaneous inference, Journal of Multivariate Analysis, 4, 224-234.

Hoque, H. A. A. B, Kim, J. H., \& Pyun, C. S. (2007) A comparison of variance ratio tests of random walk: A case of Asian emerging stock markets, International Review of Economics and Finance, 16, 488-502. http://dx.doi.org/ 10.1016/j.iref.2006.01.001

Hudson R., Dempsey, M., \& Keasey, K. (1996) A Note on the weak-form efficiency of capital markets: the application of simple technical trading rules to UK Stock prices-1935 to1994, Journal of Banking and Finance, 20, 1121-1132. 
Ito, M., \& Sugiyama, S. (2009) Measuring the degree of time varying market inefficiency, Economics Letters, 103, 62-64. http://dx.doi.org/ 10.1016/j.econlet.2009.01.028

Laurence, M., Ca, F., \& Qian, S. (1997) Weak-form efficiency and causality tests in Chinese stock markets, Multinational Finance Journal, 1, 291-307.

Lee, C. F., Chen, G., \& Rui, O. M. (2001) Stock returns and volatility on China's stock markets, The Journal of Financial Research, 24, 523-543. http://dx.doi.org/ 10.1111/j.1475-6803.2001.tb00829.x

Lima, E. J. A., \& Tabak, B. M. (2004) Tests of the random walk hypothesis for equity markets: evidence from China, Hong Kong and Singapore, Applied Economics Letters, 11, 255-258. http://dx.doi.org/ 10.1080/13504850410001674911

Lo, A., \& MacKinlay, A. C. (1988) Stock market prices do not follow random walks: evidence from a simple specification test, Review of Financial Studies, 1, 41- 66. http://dx.doi.org/ 10.1093/rfs/1.1.41

Malkiel, B. G. (2003) The efficient market hypothesis and its critics, Journal of Economic Perspectives, 17, 59-82. http://dx.doi.org/ 10.1257/089533003321164958

Miller, R. G. (1981) Simultaneous Statistical Inference, 2nd edition, Springer-Verlag, New York.

Mlambo, C., \& Biekpe, N. (2007) The efficient market hypothesis: evidence from ten African stock markets, Investment Analysts Journal, 66, 5-17.

N'dri, K. L. (2007) Previsibilité des rentabilités boursières: cas de la BRVM, African Review of Money Finance and Banking, supplement 2007, 39-54.

N'dri, K. L. (2007) Stock market returns and volatility in the BRVM, African Journal of Business Management, 1, 107-112

Nicolaas, G. (1997) Share market efficiency: tests using daily data for Australia and New Zealand, Applied Financial Economics, 7, 645-657. http://dx.doi.org/ 10.1080/758533856

Ojah, K., \& Karemera, D. (1999) Random walks and market efficiency tests of Latin American emerging equity markets, The Financial Review, 34, 57-72. http://dx.doi.org/ 10.1111/j.1540-6288.1999.tb00454.x

Omran, M., \& Farrar, S. V. (2006) Tests of weak form efficiency in the Middle East emerging markets, Studies in Economics and Finance, 23, 13-26. http://dx.doi.org/10.1108/10867370610661927

Padhan, P. C. (2009) The random walk hypothesis pertaining to stock prices in India: A firm level analysis, MIBES Transactions International Journal, 3, 64-79.

Phillips, P. C., \& Perron, P. (1988) Testing for a Unit Root in Time Series Regressions, Biometrica, 75, 335-346. http://dx.doi.org/ 10.1093/biomet/75.2.335

Poterba, J. M., \& Summers, L. H. (1988) Mean reversion in stock prices: evidence and implications, Journal for Financial Economics, 25, 323-348. http://dx.doi.org/ 10.3386/w2343

Regúlez, M., \& Zarraga, A. (2002) Common features between stock returns and trading volume, Applied Financial Economics, 12, 885-893. http://dx.doi.org/ 10.1080/09603100110053317

Ryoo, H. J., \& Smith, G. (2002) Korean stock prices under price limits: Variance ratio tests of random walks, Applied Financial Economics, 12, 545-553. http://dx.doi.org/ 10.1080/09603100010015789

Seiler, M.J., \& Rom, W. (1997) A historical analysis of market efficiency: do historical returns a random walk?, Journal of Financial and Strategies Decisions, 10, 49-57.

Urrutia, J. L. (1995) Tests of random walk and market efficiency for Latin American emerging markets, Journal of Financial Research, 18, 299-309. http://dx.doi.org/ 10.1111/j.1475-6803.1995.tb00568.x

Worthington, A.C., \& Higgs, H. (2004) Random walks and market efficiency in European equity markets, Global Journal of Finance and Economics, 1, 59-78.

Wright, J. H. (2000) Alternative variance-ratio tests using ranks and signs, Journal of Business and Economic Statistics, 18, 1-9. http://dx.doi.org/ 10.1080/07350015.2000.10524842

\section{(cc) EY}

This work is licensed under a Creative Commons Attribution 3.0 License. 